\title{
Cancer risk analysis of benzene, formaldehyde and acetaldehyde on gasoline station workers
}

\author{
Tanasorn Tunsaringkarn ${ }^{1 *}$, Tassanee Prueksasit ${ }^{2}$, Mingkwan Kitwattanavong ${ }^{3}$, Wattasit Siriwong' ${ }^{1}$ Saowanee Sematong ${ }^{1}$, \\ Kalaya Zapuang', Anusorn Rungsiyothin'
}

\begin{abstract}
Background: Benzene, formaldehyde and acetaldehyde are carcinogenic substances to which gasoline station workers are most likely exposed via inhalation. To evaluate these compounds in the ambient air of gasoline stations, the inhalation exposure test on workers was performed and assessed. By the appropriate intervention of wearing mask and hand washing during work shift, we determined whether or not there is cancer risk to the exposure of benzene, formaldehyde and acetaldehyde using urinary biomarkers.

Methods: A cross sectional study was conducted in 38 workers of 6 gasoline stations in Pathumwan District, Bangkok, Thailand. Inhalation and ambient air concentrations of benzene, formaldehyde and acetaldehyde were evaluated by GC/FID and HPLC/UV detectors. Urinary trans, trans-muconic acid (t,t-MA), formaldehyde and acetaldehyde concentrations detected in gasoline workers before and after appropriate intervention were analyzed by GC/FID.

Results: The average inhalation exposure concentrations of benzene, formaldehyde and acetaldehyde were 195.56, 12.60 and 5.74 $\mu \mathrm{g} / \mathrm{m3}$, respectively. The level of benzene exposure was significantly higher than the ambient air level (independent $\mathrm{t}$-test, $\mathrm{p}<0.01$ ). The average lifetime cancer risk of the workers exposed to benzene, formaldehyde and acetaldehyde was determined at the values of 2.15E-04, 1.27E-05 and 2.69E-06, respectively. Benzene and formaldehyde values were higher than an acceptable criteria defined as $1 \mathrm{E}-06$. The amount of urinary $\mathrm{t}, \mathrm{t}-\mathrm{MA}$, formaldehyde and acetaldehyde in the workers daily after 7-days appropriate intervention (wearing masks as personal protective equipment (PPE) and hand washing) was decreased. Formaldehyde and acetaldehyde, which were detected in urine, showed significantly lower than before intervention (pair t-test, $\mathrm{p}<0.001$ ).

Conclusions: Results from our study confirmed that the gasoline workers have high chances of cancer risk from daily exposure to benzene and formaldehyde. The urinary's t,t-MA, formaldehyde and acetaldehyde could be considerably used as biomarkers in gasoline station workers. An appropriate intervention, using PPE and hand washing, could reduce the cancer risk.
\end{abstract}

\section{Background}

Volatile organic compounds (VOCs) are generated through fuel used and its evaporation. The refueling of vehicles is a major source of VOCs in the ambient air [1]. Aromatic hydrocarbon levels are high particularly in specific environments such as roadsides along busy streets, parking garages and gasoline stations. Gasoline workers are directly exposed to various gasoline products via many routes: ingestion and dermal absorption, but the most likely route is by inhalation [2]. In Bangkok metropolitan area, since 2001 after the banned of leaded-fuel, the number of gasoline station with the service of gasohol has been rapidly increased [3]. It has been reported that the exposure level at the gasoline station is largely dependent on the gasoline's technical specifications such as the benzene content, emission control and the operation [4]. Because of increasing gasohol consumption, there has been an increase in carbonyl compounds, especially formaldehyde and acetaldehyde (both and benzene are designated as carcinogens [5]) in the general ambient air of Bangkok [6-7]. Exposure assessments of any toxic

*correspondence: tkalayan@chula.ac.th

'College of Public Health Sciences, Chulalongkorn

University, Bangkok 10330, Thailand.

Full list of author's information is available at the end of the article air pollutants could be used to evaluate the potential exposure to humans and the environment. The measurement of direct personal exposure is still a reliable method accessing the health impact of hazardous air pollutants [8].

It has been found that high doses of chemical exposure may overwhelm the metabolic capacity and resulted in the presence or remaining of metabolites and un-metabolites in urine. The urinary trans, trans-muconic acid (t,t-MA) is a metabolites of benzene, which is used as a biomarker of exposure [9] while formaldehyde is metabolized by aldehyde dehydrogenase into formic acid which is further oxidized to carbon dioxide or may serve as a one-carbon donor in tetrahydrofolate-dependent synthesis of purine, pyrimidine and amino acids. However, because of the rapid metabolism and exhalation, the exposure to formaldehyde does not always result in an increased blood or urine concentration of the parent compound in animals or humans [10-11].

Therefore, the development of urinary biomarkers for formaldehyde and acetaldehyde exposures could be another option for risk assessment and biomonitoring in occupational workers, along with the use of personal protection equipments (PPEs) by respiratory, hand and body in the work place as recommended by the Occupational Safety and Health Administration (OSHA) [12].

(C) 2012 Tunsaringkarn et al; licensee Herbert Publications Ltd. This is an open access article distributed under the terms of Creative Commons Attribution License (http://creativecommons.org/licenses/by/3.0), This permits unrestricted use, distribution, and reproduction in any medium, provided the original work is properly cited 
In this preliminary study, we conducted the cancer risk analysis of benzene, formaldehyde and acetaldehyde on the gasoline station workers and compared these exposures between before and after the 7-days of appropriate intervention (of wearing mask and hand-washing), by using the urinary t,t-MA, formaldehyde and acetaldehyde will be used as biomonitoring.

\section{Methods}

\section{Study area:}

Our study areas were 6 gasoline stations located in the Pathumwan district (one of the busiest areas with the most congested traffic and high level of air pollutions), Bangkok, Thailand.

\section{Sample collection and analysis:}

Samples were collected from 6 gasoline stations (Brand A: Station 1 \& 2; Brand B: Station 2 \& 3; Brand C: Satation 5 \& 6) of Pathumwan district, from May to July 2010. Twenty-four workers (4 workers from each gasoline station) were examined for the inhalation exposure and thirty-eight workers were subjects for examinations of urinary t,t-MA, formaldehyde and acetaldehyde, before and after 7-days of appropriate intervention (wearing mask and hand washing practice (which the workers agreed that could protect the exposures and were easy to do) during their work shift. The personal mask used in this study was the 3M-9913V Type GP1 (Australia Pty Limited) with an exhalation valve (Australian Standard). The Dettol hygienic original soap (Reckite Benckiser, Thailand) was used for hand washing.

All subjects were healthy and had worked for more than six months at their gasoline stations. They were interviewed for personal data, perception of the intervention practice and questioned to evaluate their personal air formaldehyde and acetaldehyde exposure using the same method as for the ambient air sampling. They were provided with a consent form before the study. Permission to conduct study on human subjects was approved by the Ethical Review Committee for Research Involving Human Research Subjects, Health Science Group, Chulalongkorn University.

A total of twelve air samples through the active sampling method were collected for $8 \mathrm{~h}$ during working hour (6.00 A.M.2.00 P.M.). Air samplings were collected using 2,4 DNPH cartridge (for formaldehyde and acetaldehyde) and activated charcoal tube (for benzene) connected to a low flow personal air pump. Both cartridge and charcoal tube were kept at $4{ }^{\circ} \mathrm{C}$ during transportation to the laboratory and were stored in a refrigerator until analysis.

\section{Air sample analysis:}

The 2,4-DNPH cartridge was extracted immediately after sampling, and eluted with acetonitrile (ACN). The extracted solution was analyzed for formaldehyde and acetaldehyde by the high performance liquid chromatography (HPLC) with a gradient mobile phase $60 / 40 \%$ of ACN/water at flow rate $1 \mathrm{~mL} / \mathrm{min}$. The de- tection was by ultraviolet (UV) detector at a wavelength of 360 $\mathrm{nm}$ [13]. For benzene, activated charcoal was extracted with carbon disulfide $\left(\mathrm{CS}_{2}\right)$, and the sample solution was analyzed by the gas chromatography (GC) with flame ionization detector (FID). The starting temperature was set at $35^{\circ} \mathrm{C}$ and programmed to increase to $120^{\circ} \mathrm{C}$ at $5^{\circ} \mathrm{C} / \mathrm{min}$ and then continued to increase from $120^{\circ} \mathrm{C}$ to $230^{\circ} \mathrm{C}$ at $20^{\circ} \mathrm{C} / \mathrm{min}$, with a temperature hold for $5 \mathrm{~min}$ at $230^{\circ} \mathrm{C}$. Both injector and detector temperatures were maintained at $300^{\circ} \mathrm{C}$.

\section{Urine samples analysis:}

Thirty-eight urinary samples $(20-50 \mathrm{~mL})$ were collected in glass containers, sealed and stored at $-20^{\circ} \mathrm{C}$ before formaldehyde and acetaldehyde analyses by GC/FID [14]. All measured values were divided by urinary creatinine $(\mathrm{Cr})$ concentration [15] for clinical chemistry analysis. The World Health Organization (WHO) has adopted guidelines for the acceptable limits of urinary creatinine concentrations between 0.3 and $3.0 \mathrm{~g} / \mathrm{L}$ [5].

\section{Cancer and non-cancer risk calculation:}

The inhalation exposures were estimated in terms of Chronic Daily Intake (CDI) for cancer and Exposure Concentration (EC) for non-cancer. The calculation of CDI and EC according to Risk Assessment Guidance for Superfund (RAGS) Part A and Part F approaches, respectively. They can be expressed as follow:

$$
\begin{aligned}
& \mathrm{CDI}=\mathrm{CA} \times \mathrm{IR} \times \mathrm{ET} \times \mathrm{EF} \times \mathrm{ED} /(\mathrm{BW} \times \mathrm{AT}) \\
& \mathrm{EC}=\mathrm{CA} \times \mathrm{ET} \times \mathrm{EF} \times \mathrm{ED} / \mathrm{AT} \\
& \text { Where; } \mathrm{CDI}(\mathrm{mg} / \mathrm{kg} / \mathrm{d})=\text { Chronic Daily Intake } \\
& \mathrm{EC}\left(\mu \mathrm{g} / \mathrm{m}^{3}\right)=\text { Exposure Concentration } \\
& \mathrm{CA}\left(\mathrm{mg} / \mathrm{m}^{3}\right)=\text { Contaminant concentration in Air }
\end{aligned}
$$

IR $\left(\mathrm{m}^{3} / \mathrm{h}\right)=$ Inhalation Rate $\left(0.875 \mathrm{~m}^{3} / \mathrm{h}\right.$ assumed for adult $)$ BW $(\mathrm{kg})=$ Body Weight $(60.54 \mathrm{~kg}$, average body weight of workers)

ET $(\mathrm{h} / \mathrm{d})=$ Exposure Time $(8 \mathrm{~h} / \mathrm{d}$ for workers $)$

$E F(d / y)=$ Exposure Frequency (350 d/y assumed for workers)

$\mathrm{ED}(\mathrm{y})=$ Exposure Duration (30 y for workers)

AT $(d)=$ Averaging Time $(70 \mathrm{y} \times 365$ for cancer or ED $\times 365$ for non-cancer)

Cancer risk was evaluated by multiplying CDI by inhalation cancer slope factor $\left(\mathrm{CSF}_{\mathrm{i}}\right)$.

Hazard quotient (HQ) for non-cancer can be calculated by dividing $\mathrm{EC}$ by the reference concentration for inhalation ( $\mathrm{RfC}$ ), as following equations.

$$
\text { Cancer risk }=\mathrm{CDI} \times \mathrm{CSF}_{\mathrm{i}}
$$

where; Cancer risk > 1.00E-6 means Carcinogenic effects of concern

Cancer risk $£$ 1.00E- 6 means Acceptable level

$$
\mathrm{HQ}=\mathrm{EC} / \mathrm{RfC}
$$


where; HQ > 1 means Adverse non-carcinogenic effects of concern

HQ $£ 1$ means Acceptable level

\section{Statistical analysis:}

All analytical measurements were performed in duplication to give value with standard deviation. All analyses were carried out with SPSS 17.0 for Windows statistical software package. Descriptive statistical analysis was evaluated on concentrations of parameters. One Way Anova: Post HOC Multiple Comparison-LSD was computed to compare mean values between ambient air and personal exposure parameters of three difference brands of gasoline station. The pair t-test compared between urinary biomarker levels between before and after appropriate intervention. Linear regression was estimated by correlation between the parameters.

\section{Results}

\section{Exposure assessment:}

Benzene, formaldehyde and acetaldehyde were classified as car- cinogens in group A, B1 and B2 respectively. The reference concentrations for inhalation (RfC), inhalation cancer slope factors (CSFi), CAS no and the time weighted average (TWA) of benzene, formaldehyde and acetaldehyde which limited by OSHA and The American Conference of Governmental Industrial Hygienists (ACGIH) were shown in Table 1.

The averages ambient air of benzene, formaldehyde and acetaldehyde measurements at gasoline stations were 140.68, 11.28 and $3.36 \mu \mathrm{g} / \mathrm{m}^{3}$, respectively (Figure 1), while average personal air exposures were 195.56, 12.60 and $5.74 \mu \mathrm{g} / \mathrm{m}^{3}$ respectively. These results showed that the personal air exposure of benzene was significantly higher than the ambient air benzene $(p<0.01)$ but there were not significantly difference for formaldehyde and acetaldehyde concentrations. Moreover, there was a significant difference between personal air exposure and the ambient air of benzene between Brand A and B of gasoline $(p<0.01$ and $p<$ 0.05 ) but not in Brand $C$. There were not significantly difference of the personal air exposure and the ambient air concentrations of benzene, formaldehyde and acetaldehyde levels of three difference brands.

Table 1: Toxicity profile of benzene, formaldehyde and acetaldehyde

\begin{tabular}{lcccccc}
\hline Chemicals & CAS no. & $\begin{array}{c}\mathbf{R f C}^{\mathbf{a}} \\
\left(\mathbf{m g} / \mathbf{m}^{3}\right)\end{array}$ & $\begin{array}{c}\text { Inhalation Can- } \\
\text { cer Slope Factor } \\
(\mathbf{m g} / \mathbf{k g} / \mathbf{d})^{-1}\end{array}$ & $\begin{array}{c}\text { Carcino- } \\
\text { genicity }^{\mathbf{c}}\end{array}$ & $\begin{array}{c}\text { TWA (ppm) } \\
\text { OSHA }^{\mathbf{d}} \text { ACGIH }^{\mathbf{e}}\end{array}$ \\
\hline Benzene & 71432 & $3.00 \times 10^{-2}$ & $2.73 \times 10^{-2 \mathrm{~b}}$ & Group A & 10 & 0.5 \\
Formaldehyde & 50000 & $9.83 \times 10^{-3}$ & $2.1 \times 10^{-2 \mathrm{f}}$ & Group B1 & 0.75 & 0.30 \\
Acetaldehyde & 75070 & $9.00 \times 10^{-3}$ & $1.0 \times 10^{-2 \mathrm{f}}$ & Group B2 & 200 & 25 \\
\hline
\end{tabular}

${ }^{a}$ Integrated Risk Information System (IRIS), ${ }^{b}$ The Risk Assessment Information System (RAIS), ${ }^{c} E P A$ cancer classification, ${ }^{\mathrm{d}}$ Occupational Safety \& Health Administration (OSHA), ${ }^{\mathrm{e}}$ American Conference of Governmental Industrial Hygienists (ACGIH), ${ }^{\mathrm{f} C a l i f o r n i a}$ Office of Environmental Health Hazard Assessment (OEHHA)

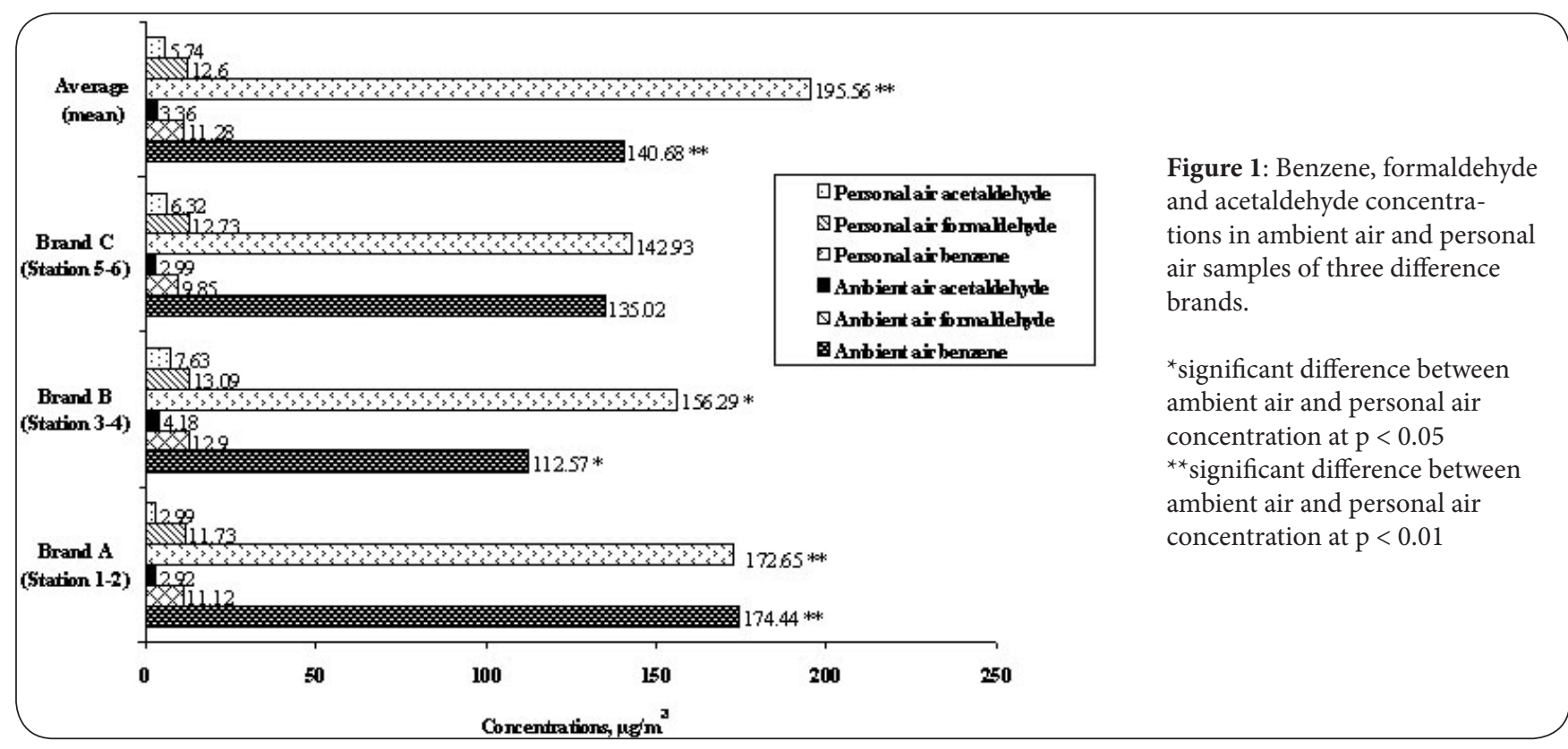


Tunsaringkarn et al. Journal of Environmental Engineering \& Ecological Science 2012,

http://www.hoajonline.com/journals/pdf/2050-1323-1-1.pdf

doi: $10.7243 / 2050-1323-1-1$

\section{Cancer risk and non-cancer assessment:}

Cancer risk assessment of gasoline station workers was determined by using the Chronic Daily Intake (CDI) for cancer and Exposure Concentration (EC) for non-cancer. Our results showed the CDIs for benzene, formaldehyde and acetaldehyde were 7.87E-03, 6.07E-04 and 2.69E-04 (mg.kg.d), while the ECs were 50.28, 3.89, and $1.71\left(\mu \mathrm{g} / \mathrm{m}^{3}\right)$, respectively. The average lifetime cancer risk of workers' exposure to benzene, formaldehyde and acetaldehyde were $2.15 \mathrm{E}-04,1.27 \mathrm{E}-05$, and $2.69 \mathrm{E}-06$, respectively. The non-cancer risk was determined by the hazard quotient (HQ) of benzene, formaldehyde and acetaldehyde exposure concentrations and found to be a ratio of $1.68,0.40$ and 0.19 respectively (Table 2).

Urinary $t, t-M A$, formaldehyde and acetaldehyde concentration: The averages of urinary levels of t,t-MA, formaldehyde and acetaldehyde of gasoline workers before the intervention practice were $0.92,27.78$ and $39.97 \mathrm{mg} / \mathrm{g} \mathrm{Cr}(1.72,44.2$ and $58.1 \mathrm{mg} / \mathrm{L}) \mathrm{re}-$ spectively, while they were $0.002,0.003$, and $6.32 \mathrm{mg} / \mathrm{g} \mathrm{Cr}(0.31$, 31.11 and $5.7 \mathrm{mg} / \mathrm{L}$ ) (Figure $2 \mathrm{~A}, 2 \mathrm{~B}, 2 \mathrm{C}$ ) after $7 \mathrm{~d}$ of the intervention practice. The urinary t,t-MA, formaldehyde and acetaldehyde concentrations of workers after the intervention practice were lower than before using these procedures. The results showed that wearing mask as PPE and hand washing procedures may decrease exposure to benzene, formaldehyde and acetaldehyde at $99.7 \%$ (from 0.92 to $0.002 \mathrm{mg} / \mathrm{g} \mathrm{Cr}$ ), $99.9 \%$ (from 27.78 to 0.003 $\mathrm{mg} / \mathrm{g} \mathrm{Cr}$ ) and $84.2 \%$ (from 39.97 to $6.32 \mathrm{mg} / \mathrm{g} \mathrm{Cr}$ ), respectively. But only formaldehyde and acetaldehyde were significantly decreased after $7 \mathrm{~d}$ of applying the measures (pair t-test, $p<0.001$ ). In addition, the urinary formaldehyde was in a moderate correlation to acetaldehyde concentrations (Linear regression; partial correlation at $0.526, p<0.001$ ).

\section{Discussion}

The use of benzene, as choice for gasoline consumption, has been continuously reduced for many years, however, health risk still persisting from exposure to this chemical in some microenvironments, e.g. gasoline gas station. There were not different of ambient air and personal air of benzene, formaldehyde and acetaldehyde levels among 6 gasoline stations. But there were significantly differences between ambient air and personal air benzene concentration of gasoline station 1 and 2 (of Brand A) $(p<0.001$ ) and station 3 and 4 (of Brand B) $(p<0.05$ ) but not at station 5 and 6) (of Brand $C$ ). The average personal benzene was significantly higher than ambient air concentrations $(p<0.01)$ while formaldehyde and acetaldehyde were slightly higher than ambient air concentrations, with no statistical difference. Most of gasoline station workers had more than one job's responsibility, e.g. gasoline-filling, cashier car washing and motor-oil check up, etc. The benzene exposure of workers in this study was higher than those reported in Greece (of 52-15 $\mu \mathrm{g} / \mathrm{m}^{3}$ ) [16]. In addition, benzene exposure was strongly correlated to those responsible for gasoline-filling (exposure levels up to $85 \mu \mathrm{g} / \mathrm{m}^{3}$ ), while other responsibilities at the station, such as car washing or working at cash machines inside an office contribute to lower exposure levels (up to 44 and $24 \mu \mathrm{g}$ / $\mathrm{m}^{3}$ respectively).

Our results also showed that there was no difference of ambient air concentrations in all 6 gasoline stations. There was a high correlation between ambient air formaldehyde and acetaldehyde concentrations (Linear regression; partial correlation at 0.781, $p<0.001$ ) as well as personal air formaldehyde and acetaldehyde concentrations (Linear regression; partial correlation at $0.670, p$ $<0.05$ ). The average personal exposure to benzene level in this study was lower than in previous studies in Thailand [17-18]. The personal formaldehyde and acetaldehyde exposures were also lower than in other countries' studies such as Korea [19], India [20] and China [21].

Regarding the health's risk assessment, our findings revealed that the average lifetime cancer risk of benzene and formaldehyde exposures via inhalation was higher than acceptable criteria of $1.00 \mathrm{E}-06$ but for the acetaldehyde, the number was acceptable. From the human epidemiological studies of highly exposed occupational cohorts, it have been demonstrated that exposure to benzene can cause acute nonlymphocytic leukemia [22]. The International Agency for Research on Cancer [23] classified formaldehyde as the causing of nasopharyngeal cancer and recent meta-analysis studies supported its association with myeloid leukemia [24]. For non-cancer risk, the hazard quotients (HQ) of benzene was more than one, showing a possible induction of adverse health effects to bone marrow, hematological and neurological toxicities [25]. But the HQs of formaldehyde and acetaldehyde were less than one which is an acceptable limit for humans. While, the hazard index $(\mathrm{HI})$ (determined by adding together the $\mathrm{HQ}$ at a specific location) was 2.27. It was much higher than one indicating that some potential adverse effects exist.

Therefore, it is quite obvious that any practices that could prevent as well as protect the gasoline station workers should be initiating and conducting. A large number of toxic chemical pollutants have been identified in the ambient air of gasoline stations. On closer reflection, the risk values in this study only evaluated important chemical exposures to benzene, formaldehyde and acetaldehyde during the worker's 8 hour shift. Other various environmental exposures via all routes for the remaining part of the day may influence the actual cancer and non-cancer risk.

Table 2. Average life time cancer risk and hazard quotients (HQ) assessments of workers

\begin{tabular}{lcccc}
\hline Parameter & $\begin{array}{c}\text { CDI } \\
(\mathbf{m g} / \\
\mathbf{k g} / \mathbf{d})\end{array}$ & $\begin{array}{c}\text { Average Life Time } \\
\text { Cancer Risk }\end{array}$ & $\begin{array}{c}\mathrm{EC}(\boldsymbol{\mu g} / \\
\left.\mathbf{m}^{3}\right)\end{array}$ & $\begin{array}{c}\text { Aver- } \\
\text { age } \\
\text { HQ }\end{array}$ \\
\hline Benzene & $7.87 \mathrm{E}-03$ & $2.15 \mathrm{E}-04$ & 50.28 & 1.68 \\
Formaldehyde & $6.07 \mathrm{E}-04$ & $1.27 \mathrm{E}-05$ & 3.89 & 0.40 \\
Acetaldehyde & $2.69 \mathrm{E}-04$ & $2.69 \mathrm{E}-06$ & 1.71 & 0.19 \\
Sum of exposures & - & $2.31 \mathrm{E}-04$ & - & 2.27 \\
\hline
\end{tabular}



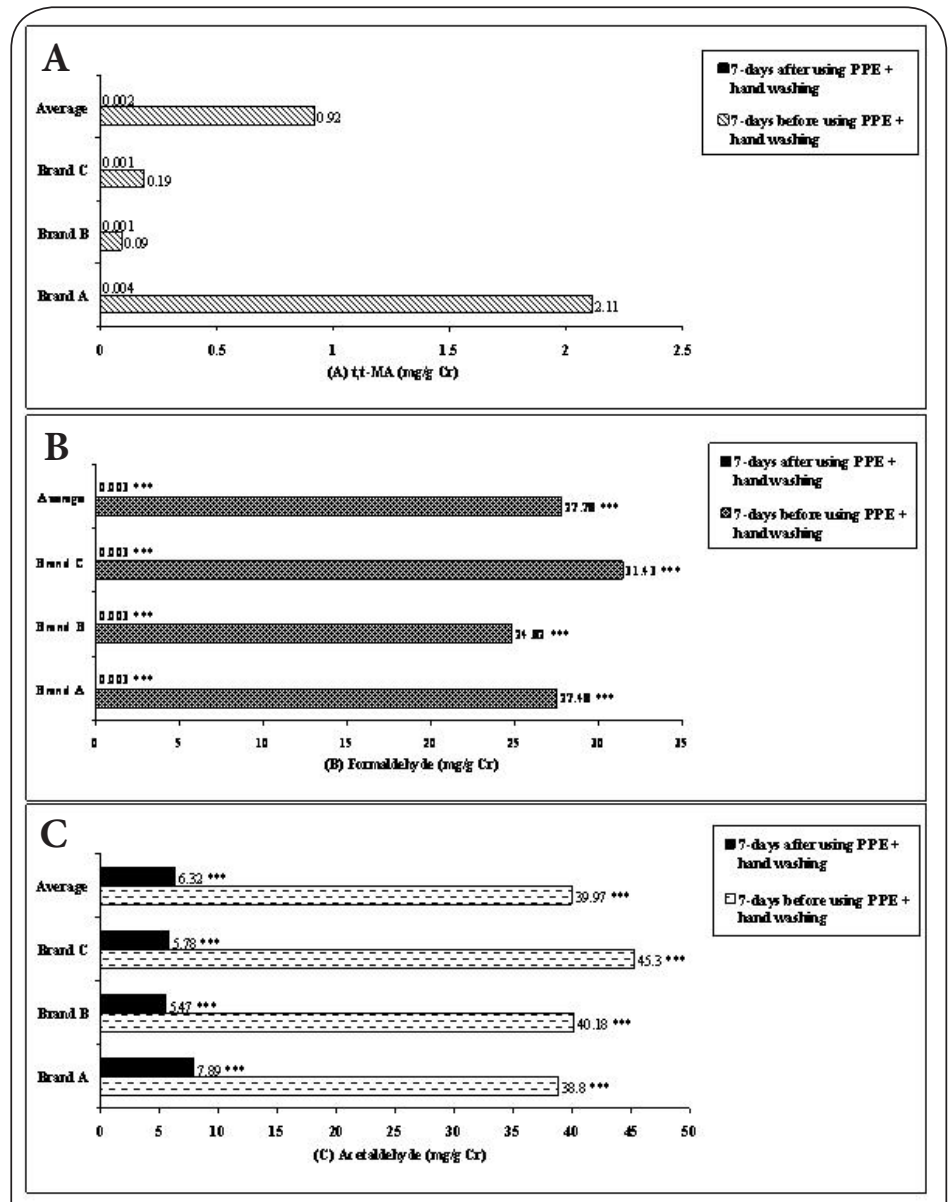

Figure 2A, 2B, 2C. Urinary t,t-MA, formaldehyde and acetaldehyde concentrations of workers of three difference brands before and after 7-days using PPE and hand washing.

* significant difference between urinary formaldehyde and acetaldehyde concentration before and after 7 -days protection at $\mathrm{p}<0.05$ ${ }^{* * *}$ significant difference between urinary formaldehyde and acetaldehyde concentration before and after 7 -days protection at $\mathrm{p}<0.001$

For the use of the urinary t,t-MA, formaldehyde and acetaldehyde as the biomarkers, none of the urinary concentrations of t,t-MA, formaldehyde and acetaldehyde were significantly different in all 6 gasoline stations. However, the urinary t,t-MA of gasoline station workers in Bangkok was higher than in a previous study [26] and reference limit of The American Conference of Governmental Industrial Hygienists (ACGIH) [5]. The urinary formaldehyde and acetaldehyde concentrations of workers after the intervention practice (wearing mask and hand washing practice) were significantly lower than before the intervention. The results suggested that wearing mask and hand washing practice may decrease the cancer risk from these exposures via inhalation and hand skin absorption. The urinary formaldehyde was correlated to acetaldehyde concentration but there was no correlation between personal exposure concentrations and urinary biomarkers of benzene, formaldehyde and acetaldehyde as in a previous found [27]. The averages of urinary formaldehyde and acetaldehyde lev- els, pre and post 7-day applying the measure, were higher than those normal reference values of $2.5-4.0$ and $0.4-0.6$ $\mathrm{mg} / \mathrm{L}$ respectively [14]. There is a lack of biological exposure indices (BEls) for urinary formaldehyde and acetaldehyde of various occupations. Urinary specimens determining the exposure concentrations should be expressed in relation to creatinine concentration. The information received from the interviewing of gasoline station workers found that only $21 \%$ workers regularly used PPE (wearing mask) and hand washing, with an average for $4.8 \mathrm{~h}$ a day, $71 \%$ of workers did it only 1 to $3 \mathrm{~d}$ a week for $2.2 \mathrm{~h}$ a day, and only $8 \%$ of the workers did not do the safety practice at all.

Our findings clearly demonstrated that the practice of using PPE (wearing mask) and hand washing were useful when the gasoline station workers conducted. In addition, the following guidelines are recommended: (1) a comprehensive knowledge on chemical toxicity must be provided; (2) an appropriate motivation program, e.g. personal safety practice, must be encouraged and operated.

\section{Conclusions}

The study demonstrated that gasoline station workers directly exposed to the cancer risk of benzene and formaldehyde exposures. Wearing mask as the PPE and hand washing were useful to reduce their exposures. While the urinary $t, t-$ MA, formaldehyde and acetaldehyde could be using as biomonitoring of these chemical exposures.

\section{Competing interests}

The Authors declare that they have no competing interests.

\section{Authors' contributions}

TT contributed in conception, research design, research management, acquisition of data, analysis, data interpretation and drafted the manuscript. TP participated in the design, statistical analysis, coordinated and assisted in drafting the manuscript. MK carried out the inhalation and ambient air analyses and participated in the data analysis and manuscript draft. WS participated in the design and revised the manuscript. SS participated giving the appropriate intervention. KZ and AR participated in data and urine sample collections. All authors read and approved the final manuscript.

\section{Acknowledgements}

This work was supported by the Thai Fogarty ITREOH Center (D43 TW007849 NIH FIC), College of Public Health Sciences and Chulalongkorn University Centenary Academic Development Project. The authors would like to thank to the Environmental Research Training Center (ERTC) for sampling devices and equipment and thank the Ethical Review Committee for Research Involving Human Research Subjects, Health Science Group, Chulalongkorn University for their suggestion and approval this study. The authors also thank to the gasoline station owners and their workers for their kind collaboration and lastly, thank to Dr. Kriangkrai Lerdthusnee for his advice and reviewing the manuscript.

\section{Author information}

${ }^{2}$ Department of General Science, Faculty of Science, Chulalongkorn 
University, Bangkok 10330, Thailand.

${ }^{3}$ National Center of Excellence for Environmental and Hazardous Waste Management (NCE-EHWM), Chulalongkorn University, Bangkok 10330, Thailand.

\section{Article history}

Editor: IIhan TALINLI, Istanbul Technical University, Turkey.

Received: 20-Feb-2012 Revised: 10-Mar-2012

Accepted: 12-Mar-2012 Published: 10-Apr-2012

\section{References}

1. P. Brimblecombe: Air composition \& chemistry. Cambridge University Press. 2nd. 1996:xii, 253 p. | Book |

2. Flanagan RJ, Meredith TJ: Volatile substances with special reference to volatile substance abuse. Human Toxicology: 1996(23): 577-622. | Book ।

3. Ministry of Energy, Department of Energy Business: Number of gas station In Thailand (in Thai). | Online |

4. Periago JF, Prado C: Evolution of occupational exposure to environmental levels of aromatic hydrocarbons in service stations. Ann Occup Hyg 2005; 49;(3.);233-40. I Article I Pubmed

5. The American Conference of Governmental Industrial Hygienists Introduction to biological exposure indices. In: TLVs $^{\circ}$ and BEIs ${ }^{\circ}$ Based on the documentation of the threshold limit values for chemical substances and physical agents \& biological exposure indices. Cincinnati, Ohio. (2010).

6. HEI (Health Effects Institute), Research Priorities for Mobile Air Toxics. HEI Communication No 2. (1993), Cambridge, MA.UK.

7. Morknoy D, Khummongkol P, Prueaksasit P: Seasonal and diurnal concentrations of ambient formaldehyde and acetaldehyde in Bangkok. Water Air and Soil Pollution 2011; 216(1-4): 693-702. | Article |

8. Carrieri M, Bonfiglio E, Scapellato ML, Macca I, Tranfo G, Faranda P, et al.: Comparison of exposure assessment methods in occupational exposure to benzene in gasoline filling-station attendants. Toxicol Lett 2006; 162;(2-3.);146-52. I Article I Pubmed

9. Scherer $G$, Renner T, Meger M: Analysis and evaluation of trans,transmuconic acid as a biomarker for benzene exposure. J Chromatogr $B$ Biomed Sci Appl 1998; 717;(1-2.);179-99. | Pubmed |

10. Gottschling LM, Beaulieu HJ, Melvin WW: Monitoring of formic acid in urine of humans exposed to low levels of formaldehyde. Am Ind Hyg Assoc J 1984; 45;(1.);19-23. | Pubmed |

11. Heck HD, Casanova-Schmitz M, Dodd PB, Schachter EN, Witek TJ, Tosun $\mathrm{T}$ : Formaldehyde $(\mathrm{CH} 2 \mathrm{O})$ concentrations in the blood of humans and Fischer-344 rats exposed to $\mathrm{CH} 2 \mathrm{O}$ under controlled conditions. Am Ind Hyg Assoc J 1985; 46;(1.);1-3. | Pubmed |

12. Occupational Safety and Health Administration, Personal protective equipment. U.S. Department of Labor Occupational Safety and Health Administration, 2003: OSHA 3151-12R. | Article |

13. Morknoy D: Carbonyl Compounds in Bangkok Ambient Air Associated with Gasohol. Doctoral dissertation, Program in Enviromental Management, Graduate School, Chulalongkorn University. 2008. I Article I.

14. De Graff ID, Nolan L, Woolley C, Fiorante A: Analysis of formaldehydeDNPH and other carbonyl-DNPH derivatives by capillary gas chromatography, Supelco, Inc., USA. 1998.

15. Slot C: Plasma creatinine determination. A new and specific Jaffe reaction method. Scand I Clin Lab Invest 1965; 17;(4.);381-7. | Pubmed |

16. Sarigiannis DA, Karakitsios SP, Gotti A, Papaloukas CL, Kassomenos PA Pilidis GA: Bayesian algorithm implementation in a real time exposure assessment model on benzene with calculation of associated cancer risks. Sensors (Basel) 2009; 9;(2.);731-55. | Pubmed Abstract | Pubmed Full text

17. Yimrungruang $D$, Cheevaporn $V$, Boonphakdee $T$, Watchalayann $P$, Helander HF: Characterization and health risk assessment of volatile organic compounds in gas service station workers. Environment Asia;
2008. 2: 21-29. | Article |

18. Thaveevong P, Panyamateekul S, Prueksasit T: Exposure risk assessment of volatile organic compounds (VOCs) of the workers at gas station in Bangkok. Engineering Journal (in Thai); 2010. 2(3): 1-12.

19. Byeon SH, Lee BK, Afanasyev V: Exposure of auto-machine and gas station workers to fine particles, heavy metals and aldehyde. IFOST: 2008 672-675.

20. Majumdar D, Dutta C, Mukherjeeb AK, Sen S: Source apportionment of VOCs at the petrol pump in Kolkala, India; exposure of worker assessment of associated health risk. Tranportation Research D: Transport and Environment. 2008. 13(8): 524-530.

21. Tang X, Bai Y, Duong A, Smith MT, Li L, Zhang L: Formaldehyde in China: production, consumption, exposure levels, and health effects. Environ Int 2009; 35;(8.);1210-24. | Article | Pubmed

22. Sonawane B, Bayliss D, Valcovic L, Chen C, Rodan B, Farland W: Carcinogenic effects of benzene--a status update and research needs to improve risk assessments: US EPA perspective. Environmental Protection Agency. J Toxicol Environ Health A 2000; 61;(5-6.);471-2. | Pubmed |

23. Formaldehyde, 2-butoxyethanol and 1-tert-butoxypropan-2-ol. IARC Monogr Eval Carcinog Risks Hum 2006; 88;1-478. | Pubmed |

24. Zhang L, Steinmaus C, Eastmond DA, Xin XK, Smith MT: Formaldehyde exposure and leukemia: a new meta-analysis and potential mechanisms. Mutat Res 2009; 681;(2-3.);150-68. | Article | Pubmed

25. U.S. Enviromental Protection Agency: Toxicological review of benzene (noncancer effects). In: support of summary information on the Integrated Risk Information System. Environmental Protection Agency, Washington, DC. 2006.

26. Wiwanitkit V, Suwansaksri J, Nasuan P: Urine trans,trans-muconic acid as a biomarker for benzene exposure in gas station attendants in Bangkok, Thailand. Ann Clin Lab Sci 2001; 31;(4.);399-401. | Article | Pubmed

27. Muttamara S, Leong ST, Arayasiri M: Benzene and lead exposure assessment among occupational bus drivers in Bangkok traffic. J Environ $\mathrm{SC}$ (China) 2004; 16;(1.);61-6. | Pubmed |

\section{Citation:}

Tunsaringkarn T, Prueksasit T, Kitwattanavong M, Siriwong W, Sematong S, Zapuang K and Rungsiyothin A: Cancer risk analysis of benzene, formaldehyde and acetaldehyde on gasoline station workers. journal of Environmental Engineering and Ecological Science 2012, 1:1.http://dx.doi.org/10.7243/2050-1323-1-1 